\title{
STUDY ON SUMMER RAINDROP SIZE DISTRIBUTION AND RETRIEVED POLARIMETRIC RADAR PARAMETER OVER LEIZHOU PENINSULA
}

\author{
Zhibin Zhou ${ }^{1,2}$, Jingjing Lv ${ }^{1,}{ }^{*}$, Shengjie Niu ${ }^{1,3}$ \\ ${ }^{1}$ Key Laboratory of Meteorological Disaster, Ministry of Education (KLME)/Joint International Research Laboratory of Climate and \\ Environment Change (ILCEC)/Collaborative Innovation Center on Forecast and Evaluation of Meteorological Disasters (CIC- \\ FEMD)/Key Laboratory for Aerosol-Cloud-Precipitation of China Meteorological Administration, Nanjing University of Information \\ Science \& Technology, Nanjing, China - lvjj@ nuist.edu.cn \\ ${ }^{2}$ Wuyi Meteorological Administration, Jinhua, China - zbzhou118@outlook.com \\ ${ }^{3}$ Nanjing Tech University, Nanjing, China - niusj@ nusit.edu.cn
}

Commission III, WG III/8

KEY WORDS: Leizhou Peninsula, Raindrop Size Distribution, $\mu-\Lambda$ Relation, Polarimetric Radar Parameters, QPE

\begin{abstract}
:
Leizhou peninsula is located in the south of Guangdong Province, near South China Sea, and has a tropical and subtropical monsoon climate. Based on observed drop size distribution (DSD) data from July 2007 to August 2007 with PARSIVEL disdrometers deployed at Zhanjiang and Suixi, the characterists of DSDs are studied. Non-linear least squares method is used to fit Gamma distribution. Convective and stratiform averaged DSDs are in good agreement with Gamma distribution, especially in stratiform case. Convective average DSDs have a wider spectrum and higher peak. Microphysical parameter differences between convective and stratiform are discussed, convective precipitation has a higher mass-weighted mean diameter $\left(D_{\mathrm{m}}\right)$ and generalized intercepts $\left(N_{\mathrm{w}}\right)$ in both areas. The constrained relations between Gamma distribution parameter $\left(\mu, \Lambda, N_{0}\right)$ is derived. The retrieved polarimetric radar parameter $\left(K_{\mathrm{DP}}\right.$, $Z_{\mathrm{DR}}, Z_{\mathrm{h}}$ ) have a good self-consistency, which can be used to improve the accuracy of $K_{\mathrm{DP}}$ calculation. $R-K_{\mathrm{DP}}-Z_{\mathrm{DR}}$ is superior to the $R$ $K_{\mathrm{DP}}, R-Z_{\mathrm{DR}}-Z_{\mathrm{h}}$ in quantitative precipitation estimation $(\mathrm{QPE})$, with a correlation coefficient higher than 0.98 .
\end{abstract}

\section{INTRODUCTION}

A large number of studies have shown that drop size distribution(DSD) varies both spatially and temporally (Bring et al., 2003; Testud et al., 2001; Wen et al., 2019; Chen et al., 2017). Accurate measurement of precipitation in radar meteorology is very important. The $Z-R$ relationship is related to the distribution of raindrop spectrum (Maki et al., 2001). It is necessary to study DSD characteristics of different regions to improve radar quantitative precipitation estimation (Chen et al., 2013). The shape of the raindrop is mainly affected by collision-coalescence, breakup, condensation, evaporation, updraft, downdraft, and horizontal wind shear and so on (Tang et al., 2014). The raindrop spectrum reflects the structural characteristics of precipitation, and the microphysical process of rainfall can be quantified by studying DSD (Raupach et al., 2015). Research on DSD has great significance in soil erosion and pollutant dispersal (Raupach et al., 2015). In addition, the study of DSD is also important in terms of communication, because raindrops absorbing and scattering cause interference to signal (Uijlenhoet et al., 2006). Ulbrich (1983) proposed a three-parameter Gamma distribution $N(\mathrm{D})=$ $N_{0} D^{\mu} e^{-\Lambda D}$ to describe the distribution of raindrops. $N_{0}$ is the intercept parameter, $\mu$ is the shape parameter, and $\Lambda$ is the slope parameter. When $\mu>0$, the curve is convex, $\mu<0$ the curve is concave. When $\mu=0$, the equation is simplified to exponential distribution. Milbrandt and Yau (2005) studied the effect of $\mu$ on water droplet sedimentation and the growth of microphysical processes. Precipitation types are generally divided into two categories: convective precipitation and stratiform precipitation, which is related to different microphysical processes (Testud et al., 2001; Milbrandt and Yau, 2005). Bringi et al. (2003) proposed the concept of continental convection and oceanic convection. The study found that there are differences between convective precipitation in different regions, the concentration of small particles near the ocean is higher than that near land. The convective precipitation in western Pacific is between the maritime-like convective precipitation and the continental-like convective precipitation (Wu et al., 2019). Chang et al. (2009) studied typhoon precipitation in the western Pacific Ocean near northern Taiwan, and parameters obtained from the typhoon precipitation in Nari and Haima indicate that these precipitations are neither marine convective precipitation nor continental convective precipitation. They guessed the characteristics of raindrops have changed due to the typhoon landing. Wen et al. (2019) studied the precipitations of four seasons in eastern China, and classified precipitations into convective, stratiform, mixed, and shallow precipitation. The frequency of shallow precipitation is the lowest, about $3 \%$. The $D_{\mathrm{m}}-\log _{10} N_{\mathrm{w}}$ in this area is closer to oceanic convection. Seliga and Bringi (1976) proposed quantitative precipitation estimation using the horizontal and vertical radar reflectivity of the particles. Additional parameters provided by the polarization radar can improve the accuracy of precipitation estimation (Brandes et al., 2002). Leizhou Peninsula is located in the southwestern part of Guangdong Province. The annual precipitation is about $1500 \mathrm{~mm}$. It is affected by weather disasters such as typhoons and heavy rains all the year round, suffering serious economic losses. Through the study of precipitation data in this region, we will have a better understanding about characteristics of different precipitation types and improve the radar estimation precipitation algorithm accuracy. The second part of the article will describe instruments, data source, research methods. The third part is characteristics of DSDs and their differences, relations. The fourth part is the

\footnotetext{
* Corresponding author
} 
quantitative precipitation estimation of polarized radar, and the final part is summary and discussion.

\section{INSTRUMENTS AND METHODS}

\subsection{Instruments and Data Source}

The instruments used in this study are Parsivel disdrometers from OTT Hydeomet, Germany. The fundamental principle is a laser sensor that emits a horizontal beam. When no particles pass through the laser beam, the receiver gets maximum voltage. When the particles pass through the laser beam, part of the laser light is blocked, reducing the received voltage. The diameter of the particle is measured by the change of the voltage, and the falling speed of the particle is calculated basing on the time of blocking. The liquid precipitation particle size measured is $0.2 \sim$ $5 \mathrm{~mm}$, and the velocity is $0.2 \sim 20 \mathrm{~m} \mathrm{~s}^{-1}, 32$ classes. Observation data used in this study is summer raindrops recording of Zhanjiang and Suixi in 2007. Two Parsivel instruments were placed in the local meteorological observation field, and the observation time was July $15 \sim$ August 22 and July $18 \sim$ August 13 respectively. The distance between two instruments is $26.4 \mathrm{~km}$.

\subsection{Methods}

In order to minimize the instrument errors, the diameter obtained by Parsivel is corrected using Battaglia et al.(2010) method. $D_{e q}^{P A R}<1 \mathrm{~mm}$ is assumed to be approximately spherical, and the axial ratio is taken as $1,1 \mathrm{~mm}<D_{e q}^{P A R}<5 \mathrm{~mm}$ axial ratio is 1.075 $0.075 D_{e q}^{P A R}, D_{e q}^{P A R}>5 \mathrm{~mm}$ axis ratio is $0.7, D_{e q}^{P A R}$ is the equivalent diameter of the instrument. The first two classes of diameter are not used because of high signal noise ratio. At the same time, with the boundary effect, the effective area of sampling will change according to the diameter of the particles, and the effective sampling area is $180 \mathrm{~mm} \times\left(30-0.5 \times D_{\mathrm{i}}\right)($ Jaffrain et al., 2011), where $D_{\mathrm{i}}$ is the corresponding particle diameter. If only a portion of the particles fall in the laser beam, the measured particle is mistaken for particles of smaller diameter, but have a faster falling velocity. At the same time, due to the influence of strong winds, large particles will have a unrealistic falling speed (Friedrich et al., 2013). We use the empirical fall speed-diameter relationship of Atlas et al. (1973) $\left(V=9.65-10.3 e^{-0.6 D}\right)$ to obtain more reliable data. We remove particles outside the $60 \%$ error area and use the proposal of Friedrich et al. (2013) to discard large particles larger than $8 \mathrm{~mm}$. The blue line in the middle of the Figure 1 represents the empirical curve of the particle diameter-falling velocity proposed by Atlas et al. (1973). The red line and the yellow line represent the curve $60 \%$ deviating from the standard curve.
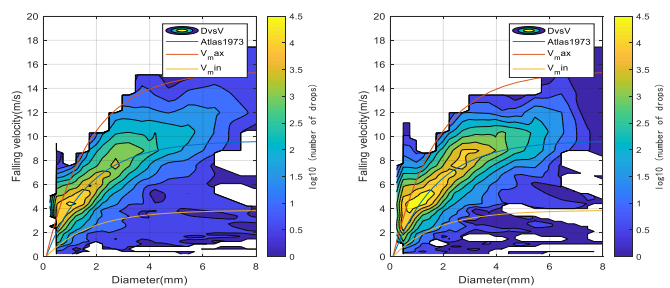

Figure 1. Particles diameter-velocity distribution in Zhanjiang and Suixi

The spectra of Zhanjiang and Suixi are similar. On the left side of the $x$-axis, there are some particles with a relatively fast falling velocity, and on the right side of the $\mathrm{x}$-axis, a small number of large particles with a slow velocity are found. There are few particles larger than $8 \mathrm{~mm}$.
With the obtained particle data, the following physical parameter can be calculated:

number concentration of raindrops

$$
N\left(D_{i}\right)=\sum_{i=3}^{32}\left(\frac{\mathrm{n}_{i j}}{A_{i} \times \Delta t \times V_{j} \times \Delta D_{i}}\right)
$$

where $\quad D_{\mathrm{i}}=$ particle diameter

$\mathrm{n}_{\mathrm{ij}}=$ number of particles with diameter $\mathrm{i}$ and velocity $\mathrm{j}$

$A_{\mathrm{i}}=$ effective sampling areas

$\Delta t=$ sampling time interval

$V_{\mathrm{j}}=$ particle falling velocity

$\Delta D_{\mathrm{i}}=$ diameter interval

total number concentration

$$
N_{T}=\sum_{i=3}^{32} N\left(D_{i}\right)
$$

water content

$$
W=\frac{\pi}{6000} \times \rho_{w} \times \sum_{i=3}^{32} \sum_{j=1}^{32} \frac{n_{i j}}{A_{i} \times \Delta t} \times D_{i}^{3}
$$

where $\rho_{\mathrm{w}}=$ density of water

rain rate

$$
R=\frac{6 \pi}{10000} \times \sum_{i=3}^{32} N\left(D_{i}\right) \times V\left(D_{i}\right) \times D_{i}^{3} \times \Delta D_{i}
$$

where $\quad V_{\mathrm{j}}=$ particle falling velocity with $D_{\mathrm{i}}$ mass-weighted mean diameter

$$
D_{m}=\frac{\sum_{i=3}^{32} N\left(D_{i}\right) \times D_{i}^{4} \times \Delta D_{i}}{\sum_{i=3}^{32} N\left(D_{i}\right) \times D_{i}^{3} \times \Delta D_{i}}
$$

generalized intercept parameter

$$
N_{W}=\frac{4^{4}}{\pi \times \rho_{W}}\left(\frac{1000 \times W}{D_{m}^{4}}\right)
$$

volume median diameter

$$
2 \int_{D_{\min }}^{D_{0}} D^{3} \times N(D) \times d D=\int_{D_{\min }}^{D_{\max }} D^{3} \times N(D) \times d D
$$

horizontally polarized radar reflectivity factor

$$
Z_{h}=\frac{4 \times \lambda}{\pi^{4} \times\left|K_{w}\right|^{2}}\left[\left(1-2 \sigma_{\Phi}^{2}\right)\left\langle\left|f_{a}(\pi)\right|^{2}\right\rangle+2 \sigma_{\Phi}^{2}\left\langle f_{a}(\pi) f_{b}(\pi)^{*}\right](8)\right.
$$

where $\quad \lambda=$ radar wavelength, $5.33 \mathrm{~mm}$ in C-brand radar.

$\left|K_{\mathrm{w}}\right|^{2}=$ dielectric constant of the water phase particles $\sigma_{\Phi}=$ standard deviation of the canting angle

$\mathrm{f}_{\mathrm{a}}(\pi)=$ major axis backscattering amplitude

$\mathrm{fb}_{\mathrm{b}}(\pi)^{*}=$ conjugate complex of the major axis backward amplitude

vertically polarized radar reflectivity factor

$$
Z_{v}=\frac{4 \times \lambda}{\pi^{4} \times\left|K_{w}\right|^{2}}\left[\left(1-2 \sigma_{\Phi}^{2}\right)\left\langle\left|f_{b}(\pi)\right|^{2}\right\rangle+2 \sigma_{\Phi}^{2}\left\langle f_{a}(\pi) f_{b}(\pi)^{*}\right](9)\right.
$$

where $\quad \mathrm{fb}_{b}(\pi)=$ minor axis backscattering amplitude. differential reflectivity

$$
Z_{\mathrm{DR}}=10 \times \log _{10} \frac{Z_{\mathrm{h}}}{Z_{\mathrm{v}}}
$$

specific differential phase 


$$
K_{D P}=\frac{180 \times \lambda}{\pi}\left(1-2 \sigma_{\Phi}^{2}\right)\left\langle R e\left|f_{a}(0)-f_{b}(0)\right|\right\rangle
$$

where $\quad f_{a}(0)=$ major axis forward scattering amplitude $f_{b}(0)=$ minor axis forward scatter amplitude

\subsection{Classification of Precipitation Types}

We use the rain rate stronger than $0.002 \mathrm{~mm} \mathrm{~h}^{-1}$ as the start of precipitation, and precipitation time less than 30 minutes is ignored. One hour interval or more is considered to be a precipitation interval between two separate precipitations (Chen et al., 2017).

Precipitation are classified using Testud et al. (2001) method: Basing on the time series of rain rate, for the sample $i$, if the rain rate of samples between time series $i-5$ and $i+5$ is less than 10 $\mathrm{mm} \mathrm{h}^{-1}$, sample $\mathrm{i}$ is considered to be stratiform precipitation. Otherwise, it is classified as convective precipitation. We get 28 rain events, 11 events in Zhanjiang and 17 events in Suixi. The total number of samples was 1335 and 2813 respectively. Zhanjiang convection $29.4 \%$, stratiform $70.6 \%$, Suixi convection $25.4 \%$, stratiform $74.6 \%$.

Table 1. Rain classification results

\begin{tabular}{lll}
\hline Area & Convective & Stratiform \\
\hline Zhanjiang & 392 & 943 \\
Suixi & 714 & 2099 \\
\hline
\end{tabular}

\section{DSD CHARACTERISTIC}

\subsection{Raindrop Spectral Features and Distributions}

Figure 2 is a plot of $\log _{10} N_{\mathrm{w}}$ and $D_{\mathrm{m}}$. The dotted line in the figure is the stratiform boundary obtained by Bringi et al. (2003). The rectangle areas are maritime and continental area, the horizontal and vertical lines represent a standard deviation. In accordance with the opinions of Bringi et al. (2003), convective precipitation and stratiform precipitation distribute on both sides of the stratiform case line. The convective precipitation $D_{\mathrm{m}}$ is $2.03 \mathrm{~mm}$ and the $\log _{10} N_{\mathrm{w}}$ is 3.72 in Suixi. The corresponding stratiform precipitation $D_{\mathrm{m}}$ is $1.35 \mathrm{~mm}, \log _{10} N_{\mathrm{w}}$ is 3.35 . Zhanjiang convection $D_{\mathrm{m}}$ is $1.80 \mathrm{~mm}$, and $\log _{10} N_{\mathrm{w}}$ is 3.80 . Zhanjiang stratiform $D_{\mathrm{m}}$ is $1.18 \mathrm{~mm}$, and $\log _{10} N_{\mathrm{w}}$ is 3.53 . Precipitations in this area are neither continental precipitation nor maritime precipitation.

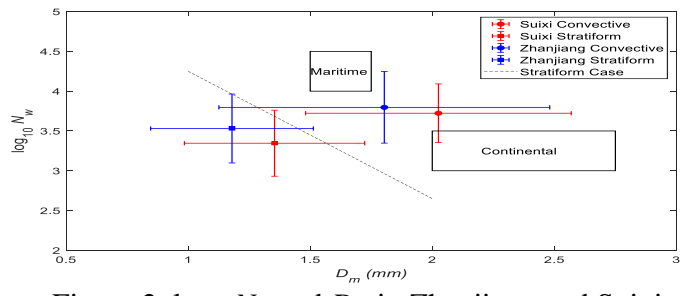

Figure 2. $\log _{10} N_{\mathrm{w}}$ and $D_{\mathrm{m}}$ in Zhanjiang and Suixi

The Gamma distribution function is $N(\mathrm{D})=N_{0} D^{\mu} e^{-\Lambda D}$. The calculation methods of parameters mainly include matrix method, maximum likelihood method and non-linear least squares method. Non-linear least squares method is used in this study to calculate the Gamma parameters. The results indicate that the Gamma distribution can well describe precipitations in the two places, the lowest correlation coefficient square is 0.64 . Although some large particles deviate from fitting curve in Zhanjiang stratiform obviously, it works better with stratiform raindrop. Generally, convective precipitation has a larger spectral width than stratiform precipitation and contains more large particles.
Convective precipitation also has a higher small particles concentration.
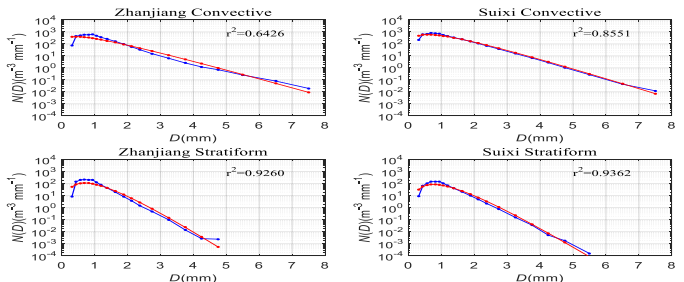

Figure 3. Average raindrop spectra in Zhanjiang and Suixi

Table 2 and 3 show integral microphysical parameters of rain. $N_{1}$, $R_{1}, W_{1}$ indicate integral parameters caused by particles smaller than $1 \mathrm{~mm}$. In total number concentration and water content, convective precipitation is much larger than stratiform precipitation. The total concentration of convective precipitation in Zhanjiang and Suixi is 622.8 and $873.7 \mathrm{~m}^{-3}$ respectively. The corresponding stratiform is 167.7 and $119.9 \mathrm{~m}^{-3}$. The water content was $0.8 \mathrm{~g} \mathrm{~m}^{-3}$ (Zhanjiang convection) and $1.39 \mathrm{~g} \mathrm{~m}^{-3}$ (Suixi convective), $0.09 \mathrm{~g} \mathrm{~m}^{-3}$ (Zhanjiang stratiform) and $0.08 \mathrm{~g}$ $\mathrm{m}^{-3}$ (Suixi stratiform).

Table 2. Zhanjiang integral rainfall parameters

\begin{tabular}{ccc}
\hline Rain type & Convective & Stratiform \\
\hline$N_{\mathrm{T}}\left(\mathrm{m}^{-3}\right)$ & 622.8 & 167.7 \\
$D_{\max }(\mathrm{mm})$ & 6.5 & 4.25 \\
$W\left(\mathrm{~g} \mathrm{~m}^{-3}\right)$ & 0.8 & 0.09 \\
$R\left(\mathrm{~mm} \mathrm{~h}^{-1}\right)$ & 18.3 & 1.6 \\
$N_{1} / N_{\mathrm{T}}(\%)$ & 66.1 & 82.2 \\
$R_{1} / R(\%)$ & 7.9 & 29.1 \\
$W_{1} / W(\%)$ & 14 & 40.1 \\
\hline
\end{tabular}

Table 3. Suixi integral rainfall parameters

\begin{tabular}{ccc}
\hline Rain type & Convective & Stratiform \\
\hline$N_{\mathrm{T}}\left(\mathrm{m}^{-3}\right)$ & 873.7 & 119.9 \\
$D_{\max }(\mathrm{mm})$ & 6.5 & 4.75 \\
$W\left(\mathrm{~g} \mathrm{~m}^{-3}\right)$ & 1.39 & 0.08 \\
$R\left(\mathrm{~mm} \mathrm{~h}^{-1}\right)$ & 33.7 & 1.6 \\
$N_{1} / N_{\mathrm{T}}(\%)$ & 63.3 & 75.6 \\
$R_{1} / R(\%)$ & 5.4 & 21.3 \\
$W_{1} / W(\%)$ & 10.1 & 30.9 \\
\hline
\end{tabular}

\subsection{Correlation between Spectral Parameters}

$\mu \Lambda N_{0}$ are the main parameters in Gamma distribution. The shape parameter $\mu$ is often considered as a constant, $\Lambda$ and $N_{0}$ is diagnostic parameter. These three parameters are not independent (Ulbrich, 1983; Zhang et al., 2001). Zhang et al. (2001) and Brandes et al. (2003) proposed a constraint relationship between the parameters of Gamma distribution, and proposed a polynomial formula to fit $\mu-\Lambda$. The formula is as following:

$$
\Lambda=0.0365 \times \mu^{2}+0.735 \times \mu+1.935
$$

Since $\mu$ and $\Lambda$ have a fluctuating value when the rain rate is small, and the large value corresponding to small particles is considered to be instrumental error rather than physical process (Zhang et al., 2003). In order to reduce the impact of sample error, data filtering is required. Zhang et al. (2003) fitted $\mu-\Lambda$ relationship using samples with rain rate $R>5 \mathrm{~mm} \mathrm{~h}^{-1}$ and total number count $C_{\mathrm{t}}>$ 1000. Cao et al. (2008) suggested fitting data with $0<\Lambda<20$ $\mathrm{mm}^{-1}$. Chen et al. (2017) used samples with a particle number more than 300 for the $\mu-\Lambda$ relationship. Here we use the Chen et 
al. (2013) method to filter out samples with a total particle counts less than 1000 . Since the $\mu-\Lambda$ relationship in the stratiform precipitation is weak, we only discuss the $\mu-\Lambda$ relationship in the convective precipitation. The least squares method is used to fit the quadratic polynomial, and the following results are obtained:

(1) Zhanjiang area: $\Lambda=0.0403 \times \mu^{2}+0.6297 \times \mu+1.1847$

(2) Suixi area: $\Lambda=0.0367 \times \mu^{2}+0.671 \times \mu+1.1745$

The coefficients of correlation are 0.9932 and 0.9789 , respectively, and the $\mu-\Lambda$ relationship is almost same in two areas. In Figure 4 we compare our results with others. When the $\mu$ value is relatively large, Zhanjiang, Suixi is between the curves of Tang et al. (2014) Beijing and Zhang et al. (2003). When the value of $\mu$ is small, the results are similar with the result of Yangjiang.

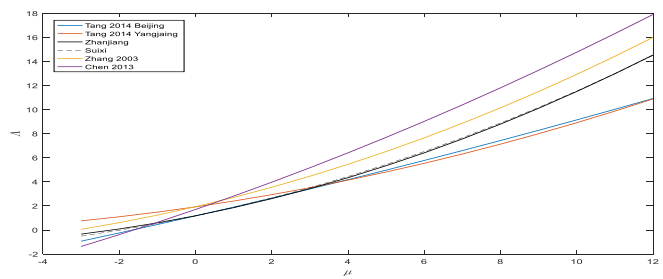

Figure 4. $\mu-\Lambda$ curve in different areas

As for the relationship between $N_{0}$ and $\mu$, the calculation of $N_{0}$ $\left(\mathrm{m}^{-3} \mathrm{~mm}^{-1-\mu}\right)$ depends on the value of $\mu$, which indicates that there is a computational correlation between the two calculated parameters, thus making it difficult to distinguish whether there is a physical correlation (Bumke et al., 2011) between $N_{0}$ and $\mu$. Chen et al. (2017) expressed the relationship between $N_{0}$ and $\mu$ with an exponential form:

$$
N_{0}=323 \times e^{1.5 \mu}
$$

We use a similar method to calculate $N_{0}$ and $\mu$, (Figure 5 is the fitting result). The fitting results show a linear fit correlation between $\mu$ and $\log _{10}\left(N_{0}\right)$ in Zhanjiang, Suixi. The correlation coefficients are 0.96 and 0.85 . Because small value change in $\mu$ will cause great change in $N_{0}$, this relationship is not suitable for retrieving.
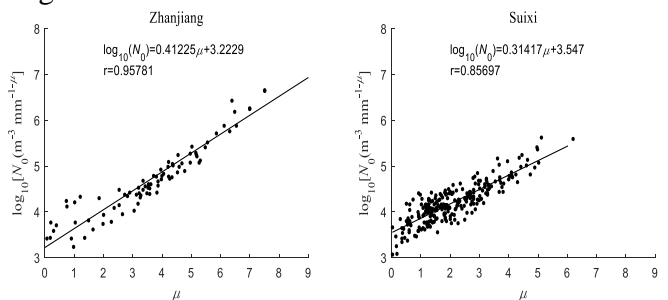

Figure 5. $\mu$ and $\log _{10}\left(N_{0}\right)$ fitting result

\section{POLARIZATION RADAR AND PRECIPITATION ESTIMATION}

\subsection{Radar Parameter Correlation}

$K_{\mathrm{DP}}$ is basically not affected by radar calibration, echo attenuation, etc., and is superior in precipitation estimation. Optimizing estimation of $K_{\mathrm{DP}}$, the quantitative precipitation estimation accuracy can be improved. Scarchilli et al. (1996) pointed out that there is self-accuracy between $K_{\mathrm{DP}}-Z_{\mathrm{h}}-Z_{\mathrm{dr}}$, and the relationship between $Z_{\mathrm{h}}-Z_{\mathrm{dr}}$ and $K_{\mathrm{DP}}$ can be used to improve $K_{\text {DP }}$ accuracy.

$$
\begin{gathered}
Z_{d r}=10^{\frac{Z_{D R}}{10}} \\
K_{D P}\left(Z_{h}, Z_{d r}\right)=a \times Z_{h}^{b} \times Z_{d r}^{c}
\end{gathered}
$$

where $\quad a, b, c=$ coefficients

By fitting, we find that the precipitation in both places is in good agreement with this relationship, points that deviate from the fitted line may be due to scale election effects (Kumjian and Ryzhkov, 2011).
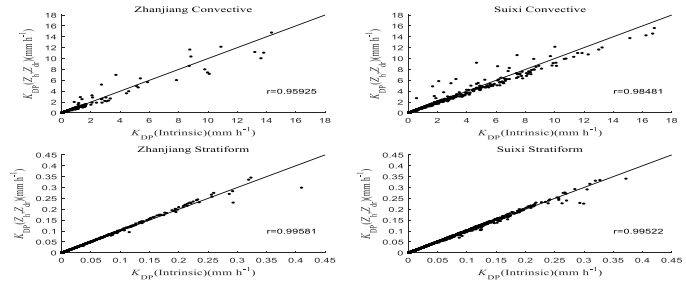

Figure 6. $K_{\mathrm{dp}}-Z_{\mathrm{h}}-Z_{\mathrm{dr}}$

\subsection{Quantitative Precipitation Estimation}

Most common algorithms for quantitative precipitation estimation using dual polarization parameters are $R-K_{\mathrm{DP}}, R-K_{\mathrm{DP}}$ $\mathrm{Z}_{\mathrm{DR}}$ and $R-Z_{\mathrm{DR}}-Z_{\mathrm{h}}$

$$
\begin{gathered}
R=\mathrm{a} \times K_{D P}^{b} \\
R=a \times K_{D P}^{b} \times Z_{D R}^{c} \\
R=a \times Z_{D R}^{b} \times Z_{h}
\end{gathered}
$$

The fitting coefficients are given in Table 4, 5, and 6, Figure 7, 8, 9 are the fitting results.

Table 4. $R$ - $K_{\mathrm{DP}}$ coefficients

\begin{tabular}{lll}
\hline Precipitation & $\begin{array}{l}\text { Coefficient } \\
\mathrm{a}\end{array}$ & $\begin{array}{l}\text { Coefficient } \\
\mathrm{b}\end{array}$ \\
\hline $\begin{array}{l}\text { Zhanjiang } \\
\text { Convective }\end{array}$ & 23.93 & 0.72 \\
$\begin{array}{l}\text { Suixi } \\
\text { Convection }\end{array}$ & 24.23 & 0.768 \\
$\begin{array}{l}\text { Zhanjiang } \\
\text { Stratiform }\end{array}$ & 18.54 & 0.694 \\
$\begin{array}{l}\text { Suixi } \\
\text { Stratiform }\end{array}$ & 15.84 & 0.679 \\
\hline
\end{tabular}

Table 5. $R-K_{\mathrm{DP}}-Z_{\mathrm{DR}}$ coefficients

\begin{tabular}{llll}
\hline Precipitation & $\begin{array}{l}\text { Coefficient } \\
\mathrm{a}\end{array}$ & $\begin{array}{l}\text { Coefficient } \\
\mathrm{b}\end{array}$ & $\begin{array}{l}\text { Coefficient } \\
\mathrm{c}\end{array}$ \\
\hline $\begin{array}{l}\text { Zhanjiang } \\
\text { Convective }\end{array}$ & 0.0026 & 0.9227 & -1.017 \\
$\begin{array}{l}\text { Suixi } \\
\text { Convection }\end{array}$ & 0.0019 & 0.9655 & -1.1156 \\
$\begin{array}{l}\text { Zhanjiang } \\
\text { Stratiform }\end{array}$ & 0.0021 & 0.9728 & -0.7806 \\
$\begin{array}{l}\text { Suixi } \\
\text { Stratiform }\end{array}$ & 0.0018 & 0.9828 & -0.8518 \\
\hline
\end{tabular}


Table 6. $R-Z_{\mathrm{DR}}-Z_{\mathrm{h}}$ coefficients

\begin{tabular}{llll}
\hline Precipitation & $\begin{array}{l}\text { Coefficient } \\
\mathrm{a}\end{array}$ & $\begin{array}{l}\text { Coefficient } \\
\mathrm{b}\end{array}$ & $\begin{array}{l}\text { Coefficient } \\
\mathrm{c}\end{array}$ \\
\hline $\begin{array}{l}\text { Zhanjiang } \\
\text { Convective }\end{array}$ & 30.28 & 0.943 & -0.5297 \\
$\begin{array}{l}\text { Suixi } \\
\text { Convection }\end{array}$ & 30.52 & 0.943 & -0.503 \\
$\begin{array}{l}\text { Zhanjiang } \\
\text { Stratiform }\end{array}$ & 29.79 & 0.968 & -0.681 \\
$\begin{array}{l}\text { Suixi } \\
\text { Stratiform }\end{array}$ & 30.41 & 0.979 & -0.7046 \\
\hline
\end{tabular}

The $R-Z_{\mathrm{DR}}-Z_{\mathrm{h}}$ algorithm estimate is not suitable for convective precipitation in Zhanjiang, it always overestimates rain rate in most cases. $R-K_{\mathrm{DP}}-Z_{\mathrm{DR}}$ algorithm has a good performance. The fitting goodness is above 0.98 , but in the estimation of convective cloud precipitation, when the rainfall is strong, underestimation occurs.
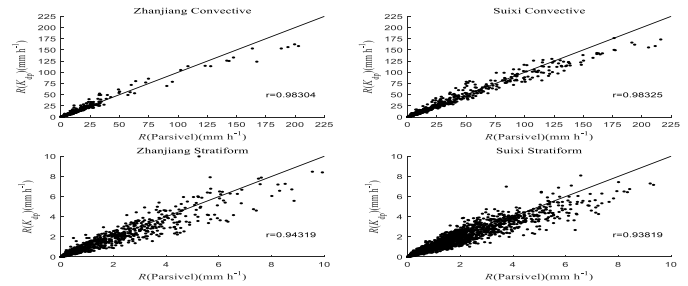

Figure 7. $R-K_{\mathrm{DP}}$
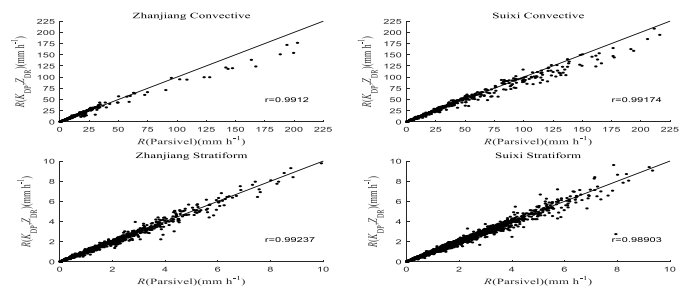

Figure $8 . R-K_{\mathrm{DP}}-\mathrm{Z}_{\mathrm{DR}}$
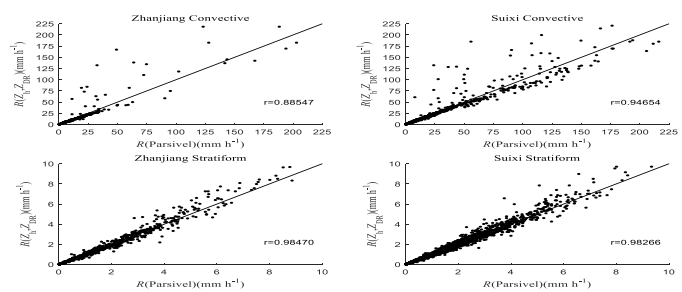

Figure 9. $R-Z_{\mathrm{DR}}-Z_{\mathrm{h}}$

\section{SUMMARY}

This study is based on the observations data of the Parsivel laser disdrometer from July to August in Zhanjiang and Suixi. Through statistical analysis, the following conclusions are drawn:

1. Convective precipitation has a larger $N_{\mathrm{w}}$ and $D_{\mathrm{m}}$ than stratiform precipitation. Although Suixi and Zhanjiang are near enough, they still show relative differences in microphysical parameter.

2. The precipitation in the Zhanjiang and Suixi conforms to Gamma distribution. DSD spectra show great differences in convective and stratiform precipitation.

3. The $\mu-\Lambda$ relationships of the two regions are basically identical, and they can be used to retrieve DSD with radar observation.
4. There is a good correlation between $K_{\mathrm{DP}}-Z_{\mathrm{h}}-Z_{\mathrm{dr}}$, which can be used to obtain a more accurate $K_{\mathrm{DP}}$. The $R-K_{\mathrm{DP}}-Z_{\mathrm{dr}}$ quantitative precipitation estimation algorithm gets a good result in this region.

The analyses above further confirm the obvious variations of DSD and similarity in different regions. The variations in DSD and instrument errors is the main error source of QPE, we will further study more sensitive QPE methods and reliable parameter relation. And try to retrieve DSD using polarization radar parameters and constrained relation.

\section{ACKNOWLEDGEMENTS}

This work was funded by the National Key Research and Development Program of China under Grant No. 2018YFC1507905, the National Natural Science Foundation of China under Grant 41675136 and 41775134.

\section{REFERENCES}

Atlas, D., Srivastava, R.C., Sekhon, R. S., 1973. Doppler radar characteristics of precipitation at vertical incidence. Reviews of Geophysics, 11(1).

Battaglia, A., Rustemeier, E., Tokay, A., Blahak, U., Simmer, C., 2010. Parsivel snow observations: a critical assessment. Journal of Atmospheric and Oceanic Technology, 27(2), 333-344.

Brandes, E. A., Zhang, G., Vivekanandan, J., 2002. Experiments in rainfall estimation with a polarimetric radar in a subtropical environment. Journal of Applied Meteorology, 41(6), 674-685. Brandes, E.A., Zhang, G., Vivekanandan, J., 2003. An evaluation of a drop distribution-based polarimetric radar rainfall estimator. Journal of Applied Meteorology, 42(5), 652-660.

Bringi, V.N., Chandrasekar, V., Hubbert, J., Gorgucci, E., Randeu, W.L., Schoenhuber, M., 2003. Raindrop size distribution in different climatic regimes from disdrometer and dual-polarized radar analysis. Journal of the Atmospheric Sciences, 60(2), 354-365.

Bumke, K., Seltmann, J., 2012. Analysis of measured drop size spectra over land and sea. ISRN Meteorology, 2012, 1-10.

Cao, Q., Zhang, G., Brandes, E., Schuur, T., Ryzhkov, A., Ikeda, K., 2008. Analysis of video disdrometer and polarimetric radar data to characterize rain microphysics in Oklahoma. Journal of Applied Meteorology and Climatology, 47(8), 2238-2255.

Chang, W.Y., Wang, T.C.C., Lin, P.L., 2009. Characteristics of the raindrop size distribution and drop shape relation in typhoon systems in the western Pacific from the 2D video disdrometer and NCU C-band polarimetric radar. Journal of Atmospheric and Oceanic Technology, 26(10), 1973-1993.

Chen, B., Hu, Z., Liu, L., Zhang, G., 2017. Raindrop Size Distribution Measurements at 4,500 m on the Tibetan Plateau During TIPEX-III. Journal of Geophysical Research: Atmospheres, 122(20), 11,092-11,106.

Chen, B., Yang, J., Pu, J., 2013. Statistical characteristics of raindrop size distribution in the Meiyu season observed in eastern China. Journal of the Meteorological Society of Japan. Ser. II, 91(2), 215-227. 
Friedrich, K., Higgins, S., Masters, F.J., Lopez, C.R., 2013. Articulating and stationary PARSIVEL disdrometer measurements in conditions with strong winds and heavy rainfall. Journal of Atmospheric and Oceanic Technology, 30(9), 20632080.

Jaffrain, J., Berne, A., 2011. Experimental quantification of the sampling uncertainty associated with measurements from PARSIVEL disdrometers. Journal of Hydrometeorology, 12(3), 352-370.

Kumjian, M.R., Ryzhkov, A.V., 2012. The impact of size sorting on the polarimetric radar variables. Journal of the Atmospheric Sciences, 69(6), 2042-2060.

Maki, M., Keenan, T.D., Sasaki, Y., Nakamura, K., 2001. Characteristics of the raindrop size distribution in tropical continental squall lines observed in Darwin, Australia. Journal of Applied Meteorology, 40(8), 1393-1412.

Milbrandt, J. A., Yau, M.K., 2005. A multimoment bulk microphysics parameterization. Part I: Analysis of the role of the spectral shape parameter. Journal of the Atmospheric Sciences, 62(9), 3051-3064.

Raupach, T.H., Berne, A., 2015. Correction of raindrop size distributions measured by Parsivel disdrometers, using a twodimensional video disdrometer as a reference. Atmospheric Measurement Techniques, 8(1), 343-365.

Scarchilli, G., Gorgucci, V., Chandrasekar, V., Dobaie, A., 1996. Self-consistency of polarization diversity measurement of rainfall. IEEE Transactions on Geoscience and Remote Sensing, 34(1), 22-26.

Seliga, T.A., Bringi, V.N., 1976. Potential use of radar differential reflectivity measurements at orthogonal polarizations for measuring precipitation. Journal of Applied Meteorology, $15(1), 69-76$.

Tang, Q., Xiao, H., Guo, C., Feng, L., 2014. Characteristics of the raindrop size distributions and their retrieved polarimetric radar parameters in northern and southern China. Atmospheric Research, 135, 59-75.

Testud, J., Oury, S., Black, R. A., Amayenc, P., Dou, X., 2001. The concept of "normalized" distribution to describe raindrop spectra: A tool for cloud physics and cloud remote sensing. Journal of Applied Meteorology, 40(6), 1118-1140.

Thurai, M., Gatlin, P.N., Bringi, V.N., (2016). Separating stratiform and convective rain types based on the drop size distribution characteristics using $2 \mathrm{D}$ video disdrometer data. Atmospheric Research, 169, 416-423.

Uijlenhoet, R., Torres, D.S., 2006. Measurement and parameterization of rainfall microstructure. Journal of hydrology, $328(1-2), 1-7$

Ulbrich, C.W., 1983. Natural variations in the analytical form of the raindrop size distribution. Journal of Climate and Applied Meteorology, 22(10), 1764-1775.

Wen, L., Zhao, K., Wang, M., Zhang, G. (2019). Seasonal Variations of Observed Raindrop Size Distribution in East China. Advances in Atmospheric Sciences, 36(4), 346-362.
Wu, Z., Zhang, Y., Zhang, L., Lei, H., Xie, Y., Wen, L., \& Yang, J. (2019). Characteristics of summer season raindrop size distribution in three typical regions of western Pacific. Journal of Geophysical Research: Atmospheres, 124(7), 4054-4073.

Zhang, G., Vivekanandan, J., \& Brandes, E. (2001). A method for estimating rain rate and drop size distribution from polarimetric radar measurements. IEEE Transactions on Geoscience and Remote Sensing, 39(4), 830-841.

Zhang, G., Vivekanandan, J., Brandes, E. A., Meneghini, R., \& Kozu, T. (2003). The shape-slope relation in observed gamma raindrop size distributions: Statistical error or useful information?. Journal of Atmospheric and Oceanic Technology, 20(8), 1106-1119. 